\title{
CUENTOS Y POESÍAS
}

\author{
HÉCTOR LUIS OJEDA \\ Facultad de Ciencias Económicas \\ Universidad Nacional del Nordeste
}

ARGENTINA 


\begin{tabular}{lc}
\hline$>176$ & HÉCTOR LUIS OJEDA \\
& CUENTOS Y POESÍAS \\
Pags. $175-182$ \\
\hline
\end{tabular}

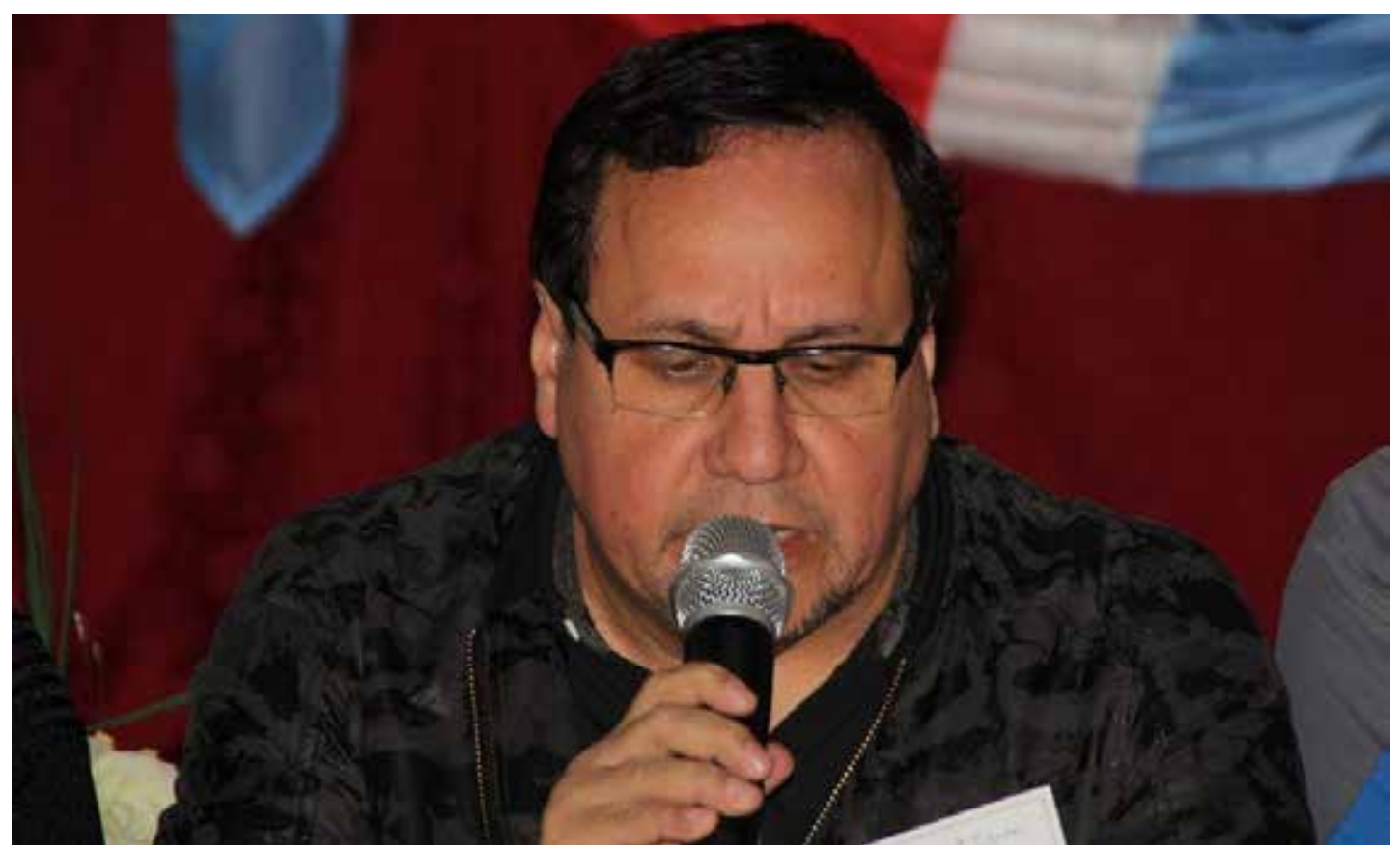

ació en Mercedes (Prov. De Corrientes), el 10 de octubre de 1963 - Desarrolló su
niñez en Resistencia (Prov. Del Chaco). Realizó parte de la primaria en la Escuela
$\mathrm{N}^{\circ} 2-$ Raúl B. Díaz y finalizó en la Escuela Nacional $\mathrm{N}^{\circ} 54$ - Ejercito Argentino - y continuó toda la secundaria en la Escuela Normal Superior Domingo F. Sarmiento (Son todas instituciones de la ciudad de Resistencia de la Provincia del Chaco).

Desarrolla sus actividades laborales desde 1987 en la Facultad de Ciencias Económicas, es Técnico en Administración y Gestión de Instituciones Universitarias (Carrera Universitaria).

Participación en Concurso de Trabajos Monográficos marco de los festejos del $60^{\circ}$ Aniversario de Creación de la Facultad de Ciencias Económicas, tema: Responsabilidad Social Universitario, obtención Mención Especial Categoría No docente (2011).

Participación Asistencia y presentación de la antología El Séptimo Poema - Poesía y Cuentos del Grupo Literario César Enrique Juncos, como invitado especial (2012).

Participación en primera muestra Taller de Poesía y Narrativa "Libre Bajo Palabra" en la consigna "Confieso que Escribo", auspiciado por la Dirección de Letras Instituto de Cultura, Casa de las Culturas e Instituto de Cultura "Chaco Todas las Culturas”. Coordinación: María Fernanda Sánchez Barros (2013). 
Realización Taller de Poesía y Narrativa y participación en antología literaria en "Libre Bajo Palabra" - La Mesa Vertical - "nostalgias circulares de la muerte y otros eclipses"; Coordinación: María Fernanda Sánchez Barros (2014).

III ${ }^{\circ}$ Concurso Internacional de Poesía, Cuento y Carta - "Mención de Honor" al poema: "UNO BUSCA” en género de Poesía -Brandsen (La Plata-Bs. As.) Publicación en Antología 2015 Lemu Montún Ediciones.

XLIII CONCURSO INTERNACIONAL DE POESIA y NARRATIVA - LIBRO DIGITAL - "ELEGIDOS 2014" Instituto Cultural Latinoamericano "Segundo Premio" en género: Poesía. Junín (Buenos Aires - Argentina) (2015).

XLV CONCURSO INTERNACIONAL DE POESÍA y NARRATIVA "PALABRAS SIN FRONTERAS” 2015 - Instituto Cultural Latinoamericano "6a MENSIÓN ESPECIAL" en género: Poesía. Junín (Buenos Aires - Argentina).

Participación en $13^{\text {a }}$ Maratón Nacional de Lectura Fundación Leer - Biblioteca Popular Hipólito Yrigoyen - Municipalidad de Resistencia - Resistencia (Chaco - Argentina).

PREMIOS GUKA DE NARRATIVA Y POESÍA 2015 - Tercera Mención Especial en Poesía "LA MANCHA DE HUMEDAD” - Biblioteca Nacional (Ciudad Autónoma de Buenos Aires).

XLVII CONCURSO INTERNACIONAL DE POESÍA Y NARRATIVA "Confluencia de Palabras 2015” Instituto de Cultura Latinoamericano "Séptima Mención Especial” Género: Poesía. Junín (Buenos Aires - Argentina).

Sociedad de Escritores Regionales Brandsen - La Plata "IVo CONCURSO INTERNACIONAL DE POESÍA, CUENTO Y CARTA" - "Mención de Honor" en Poesía "ATURDIDOS”. (La Plata - Bs. As.).

Asistencia y Aprobación al curso Taller de Lectura y Análisis Literario, dictado por el Prof. Mario Doldan - ciclo lectivo 2015 - en el Centro Cultural Nordeste dependiente de la Extensión Universitaria de la UNNE (2015).

$1^{\circ}$ de Julio / Ciclo de Autores y Personajes, realizado en el CCN - La obra: "AÚN QUEDA ALGO POR DECIR" - Basado en el cuento de mi autoría: "El Calor de Mierda Que Nunca Falta”. 


\begin{tabular}{lc}
\hline$>178$ & $\begin{array}{l}\text { HÉCTOR LUIS OJEDA } \\
\text { CUENTOS Y POESÍAS } \\
\text { Pags. } 175-182\end{array}$ \\
\hline
\end{tabular}

Concurso "Alfonsina Storni” S.A.D.E. Filiar Marcos Suarez -"NO CREAS TUS MENTIRAS" - Cuarta Mención / Genero: Cuento. (Marcos Juárez - Córdoba) - 17 de Julio de 2016. Publicación en Antología 2016.

Participación en Recital de Poesía: "De Cuerpos y Formas, De palabras y Cinceles" - Martes 26 de julio de 2016. En el Centro Cultural Nordeste (CNN).-

Concurso "S.A.D.E. Sociedad Argentina de Escritores (Filial Sáenz Peña)" $2^{\circ}$ Distinción, Medalla y Diploma de Honor - 12 de noviembre de 2016.-

Diploma de participación al Concurso Organizado por la Biblioteca Legislativa "Ramón de las Mercedes Tissera" - Facultad de Humanidades - UNNE, SOCIEDAD ARGENTINA DE ESCRITORES (SADE) Filial Chaco y Librería - Editorial ConTexto - Diciembre de 2016.-

Participación con el cuento corto: PIEL DE LUNA. En "SEMÁNTICAS DEL DESEQUILIBRIO" Revista Literaria y Cultural No 4 - Enero/2017 (Revista Digital).

Participación con dos (2) poemas: FUEGOS y GUERRA EN LA PIEL. En “ANTOLOGÍA 2017” -La gota- Slam de poesía oral de Corrientes (2017).

$55^{\circ}$ CONCURSO INTERNACIONAL DE POESÍA Y NARRATIVA "Hermanando Palabras 2017" Instituto de Cultura Latinoamericano "Mención de Honor" Género: Poesía. Junín (Buenos Aires - Argentina) - 22 de abril de 2017.-

$1^{\circ}$ Encuentro de Escritores, Poetas y Declamadores "Humahuaca en Poesías" - ciudad histórica de Humahuaca, Provincia de Jujuy - 12,13 y 14 de mayo de 2017.-

XVI Encuentro Latinoamericano de Escritores “MADRE DE CIUDADES" - Santiago del Estero (Adhesión al 464 Aniversario de la Noble Ciudad) - 13, 14, 15 y 16 de Julio de 2017.-

S.A.D.E. - Seccional Rosario, Santa Fe, Argentina / Encuentro Nacional e Internacional de Escritores/ "Rosario... luz y palabra" - 8, 9, 10 de septiembre de 2017.

hectorojeda63@hotmail.com 


\section{RAPSODIA II}

Quiero abrazar tu ausencia para recordarte y caer en la orla mecedora de tus rizos

pretendo invocar tu cuerpo con ansiedad de primavera y sujetarme a tu talle estampa amanecida en el éxtasis de mi memoria.

\section{Héctor Luis Ojeda}

\section{TE ESTREMECES BUENOS AIRES}

Mundanal de gente absorbidas en sus vidas golpean los nervios contra la marcha

desorden calado de mal humor del estrés angustioso con aromas escupidos en hollín

porquerías sueltas por las calles chocan con los pasos alterados de travesuras de papeles telas

latas

ruina constante

de arreglos y desarreglos

el herrumbre marca los viejos vestigios abatidos por nuevas edificaciones

sendas grises con líneas amarillas bordadas por acuarelas enamoradas en la placidez de adoquines y atrás queda el vendaval

del atroz vehicular como monedas lanzadas al Río de la Plata

buscan en las actividades la supresión punteada por cuentos de pasos que vagan sin rumbo.

\section{Héctor Luis Ojeda}

$52^{\circ}$ Concurso Internacional de poesía Y Narrativa “ABRAZANDO PALABRAS" 2016

Instituto Cultural Latinoamericano"10 Mención de Honor". 


$\begin{array}{ll}>180 & \text { HÉCTOR LUIS OJEDA } \\ \text { CUENTOS Y POESÍAS }\end{array}$

\section{TERESA Y EL SOL}

El rostro pálido de Teresa, con el maquillaje arruinado, y sus finos labios delineados por un violáceo deslucido. La mano manchada con sangre seca, sujeta el volante. Los dedos temblorosos sostienen un cigarrillo consumido, las cenizas extraviadas en la oscura alfombra del auto. Los destellos de luces de la ruta pegan sobre el parabrisas, se enredan en el lila de las uñas y su voz áspera repite un nombre:

-Antonio... Antonio... Antonio.

Intenta escapar de la mala jugada del destino, y lleva en el portaequipajes la prueba de su delito.

La desesperación se presenta al recordar los insultos, la riña a bofetones y el estampido aquel que la paralizó. Quiere olvidar todo. Las lágrimas rebalsan sus parpados, el sudor pega el pelo blanco de peluca en la cara.

Vuelve a revivir el engaño, las palabras de él creyendo que con un beso en sus labios y un ramo de rosas, podría convencerla "de que solo fue algo sin importancia".

Con manotazos comenzó el escándalo. No podía detener su furia y él no dejaba de repetir:

-Perdón no fue mi intención. iTenés que creerme! iTenés que creerme!

Pero ella los vio muy bien: juntos con la desconocida esa, un beso apasionado, un toqueteo cariñoso en las nalgas, para desaparecer ambos en el gentío del Centro Comercial, intentó en vano seguirlos.

Una cachetada sonora en la cara de Antonio, y luego el forcejeo. Ella cae contra la mesita de noche -en donde usualmente guarda un arma-, y lo extrae, "sin apuntar" dispara.

Un bocinazo la retorna al presente, los reflejos cesan con los rayos solares que tiemblan en su cuello, descubren los ojos azules, enrojecidos. Teresa y el sol se muestran en un contorno de oro, y del otro lado, en la plenitud de la luz el rostro denso -ya sin maquillaje-, demacrado por la vigilia.

A un costado de la ruta se detiene, mira las aguas iluminadas. Baja del auto, abre el baúl y saca el pesado cuerpo de Antonio, reteniéndolo por un momento en el borde del paragolpes, se funde en un último abrazo, y besa sus labios sin vida.

Después Teresa levanta a su amado, cruza el pavimento solitario a pasos presurosos, alcanza las arenas de la playa, sin aliento llega y se desploma, siente el frio líquido que la empapa. Con el último esfuerzo y ayudada por las olas, lo suelta. Los ojos cargados de lágrimas, siente los fuertes latidos del remordimiento en su pecho, mientras el cuerpo de Antonio flota, se aleja de la playa, hundiéndose lentamente en el mar.

El sol baña la piel de Teresa, a medida que retrocede despojándose de sus prendas de travestido, se quita la peluca, queda desnuda su verdad. Se sienta cerca de las aguas y llora por el dolor de su amarga condena. 


\section{Héctor Luis Ojeda}

$55^{\circ}$ Concurso Internacional de Poesía y Narrativa "Hermanando Palabras" 2017

Instituto Cultural Latinoamericano

"Mención de Honor"

\section{NO CREAS TUS MENTIRAS}

Laura no puede dormir, escucha golpes, semejantes a gotas cayendo de un grifo. Ella sabe de dónde provienen los ruidos, vienen del sótano.

La luna llena entra por la ventana y compone la noche ideal. Ella no puede conciliar el sueño, ve fantasmas en las sombras, los golpes la aturden, escucha voces que le dicen: Él está ahí.

Desvelada por los ruidos que no cesan. Cierra los ojos, se ve acunada en los cálidos brazos de su abuela y reviven las palabras:

-Niña si no te duermes, bajaré al sótano y soltaré al monstruo.

Entonces, el temor recorría su cuerpo y de la nada surgían: manos grandes que amordazan sus labios, garras lanudas acariciándola... nunca pudo descubrir ese milagro de la abuela que le causaba un aterrador escalofrío. Luego entre risas y gritos, el sueño la vencía. Cuando Laura despertaba, al otro día, veía a su madre apartar las cortinas, para que el sol de la mañana invada su cuarto.

Es tan real lo que vive en ese momento como los repentinos golpes que escucha y la retornan a la realidad, en casa de su difunta abuela y junto a su marido Federico. Recuerda también, que después de dos meses de haber restaurado la casa, no se atrevió a bajar al sótano, o tan siquiera a abrir la puerta que conduce a su interior.

Ahora no se atreve a despertar a Federico, algo le dice que no lo haga. Igual siente sed y se levanta, sin encender el velador, y a tientas llega a la cocina. Las sombras, el reflejo blanquecino de la puerta de la heladera que marca el bosquejo de su rostro la orientan. Se sirve un poco de agua, algo la toca, y un escozor punzante la acaricia por dentro. Del susto suelta el vaso, que cae estrepitosamente. Un ronco grito se le escapa de la garganta, enciende la luz, ve en el suelo el vaso roto, la mesa y las sillas movidas; siente en el pecho su corazón agitado. Regresa al dormitorio, cruza frente a la puerta del sótano. Un golpe aún más fuerte la paraliza, mira el picaporte, se mueve. Alguien de adentro intentara salir -pensó-. Laura espantada, tapa con sus manos un grito, no quiere despertar a su marido. La puerta deja de temblar y cesan los golpes. Corre a la cama, se acuesta tratando de no mover las cobijas. Queda temblorosa por varios minutos, trata de calmarse. La luz de la luna palpa su piel. Y se descubre en la penumbra justo en dirección a ella, en el espejo del antiguo ropero de la abuela, sus grandes ojos azules 
-siempre fueron marrones-. Comienzan los espasmos repentinos, que la encorvan, llevándola a la posición fetal, su cara se llena de pelos, al igual que su cuerpo, surgen dos grandes orejas puntiagudas. No es ya una mujer, sino un animal. Laura mira sus manos convertidas en garras, y comienza a bracear con furia. Federico se despierta, sale de la cama, enciende el velador y descubre los ojos de la bestia que lo miran rabiosos y un feroz hocico jadeante, cargados de filosos dientes amenazantes.

Laura desgarra las sábanas en girones, rompe en mil pedazos el vidrio de la ventana y sin poder detenerse, escapa por las calles desiertas bañadas por la luna llena.

\section{Héctor Luis Ojeda}

Concurso “Alfonsina Storni” S.A.D.E. Filial Marcos Juárez 2016

CUARTA MENCIÓN en genero CUENTO.

Publicado en Antología 2016 Cheché Gómez Lestani en S.A.D.E.

Sociedad Argentina de Escritores Seccional Chaco. Homenaje a un Presidente Ejemplar. 